\title{
Comparison of bio-inspired algorithms applied to the hospital mortality risk stratification
}

\author{
Autores \\ Jesús Silva, Yaneth Herazo-Beltrán, Freddy Marín-González, Noel Varela, \\ Omar Bonerge Pineda Lezama, Pablo Palencia, Carlos Vargas Mercado
}

\begin{abstract}
The construction of patient classification (or risk adjustment) systems allows comparison of the effectiveness and quality of hospitals and hospital services, providing useful information for management decision making and management of hospitals. Risk adjustment systems to stratify patients' severity in a clinical outcome are generally constructed from care variables and using statistical techniques based on logistic regression (RL). The objective of this investigation is to compare the hospital mortality prediction capacity of an artificial neural network (RNA) with other methods already known.
\end{abstract}

Palabras clave

Hospital mortality, Risk stratification, Intensive care unit, Artificial neural networks, Bootstrap. 